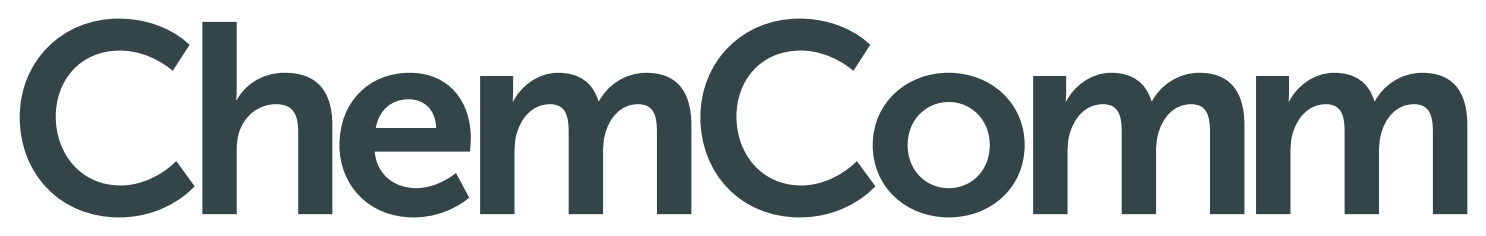

Chemical Communications rsc.li/chemcomm
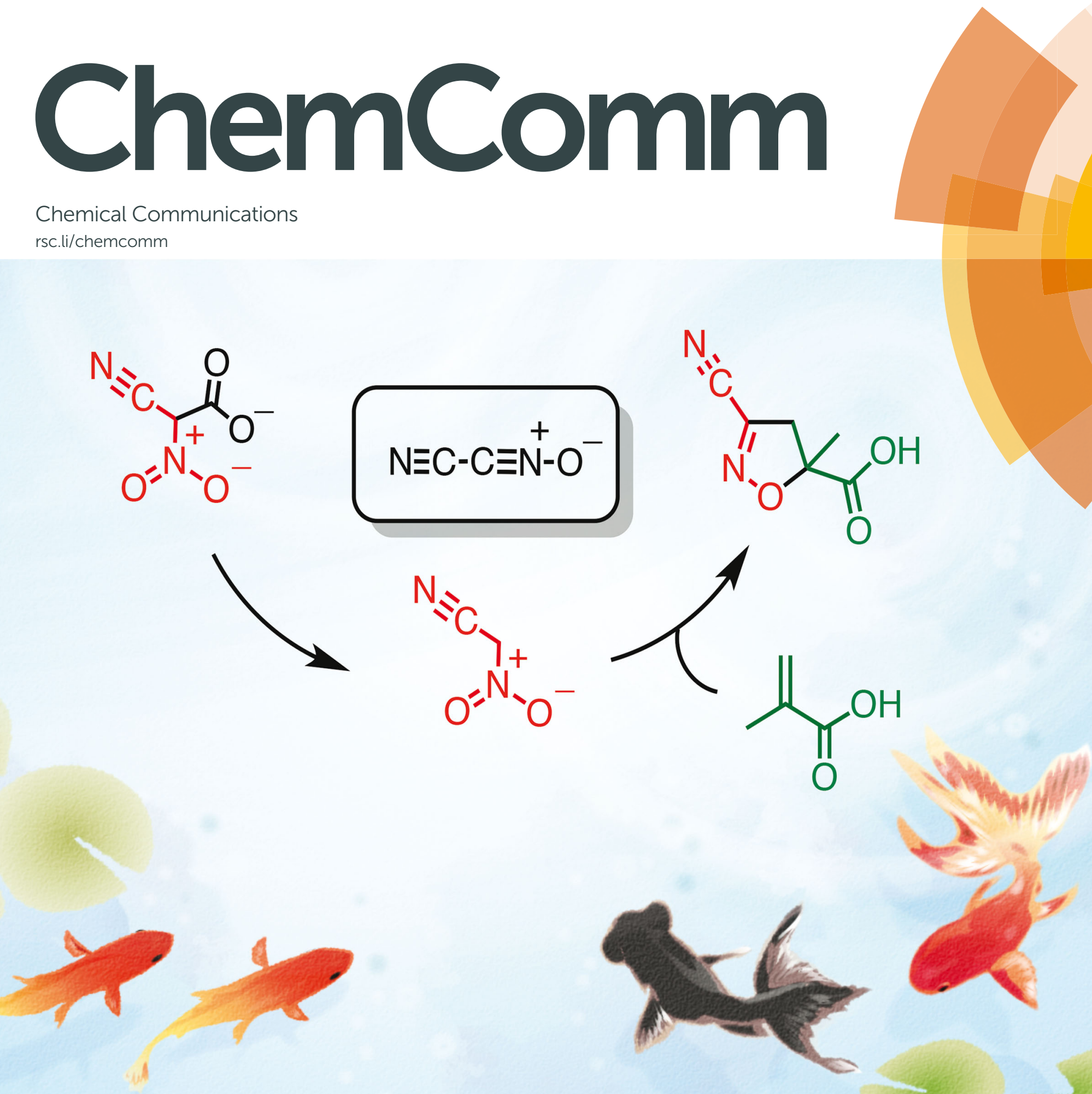
Check for updates

Cite this: Chem. Commun., 2019, 55, 7903

Received 19th May 2019,

Accepted 4th June 2019

DOI: $10.1039 / c 9 c c 03875 b$

rsc.li/chemcomm

\section{Development of a safely handleable synthetic equivalent of cyanonitrile oxide by 1,3-dipolar cycloaddition of nitroacetonitrile $\dagger$}

\author{
Nagatoshi Nishiwaki, (D) *ab Yuta Kumegawa, ${ }^{a}$ Kento Iwai (iD a and \\ Soichi Yokoyama id ab
}

\begin{abstract}
Dianionic cyano-aci-nitroacetate affords 3-cyanoisoxazol(in)es upon heating with a range of dipolarophiles in the presence of hydrochloric acid. In this reaction, nitroacetonitrile is formed as an intermediate active species, which serves as a synthetic equivalent of cyanonitrile oxide that can participate in a 1,3-dipolar cycloaddition reaction.
\end{abstract}

The 1,3-dipolar cycloaddition of cyanonitrile oxide $\mathbf{1}$ (cyanofulminate or cyanogen $N$-oxide) is a useful preparative method for the synthesis of 3-cyanoisoxazol(in)es, which is superior to other methods such as direct substitution by a cyanide, ${ }^{1}$ chemical conversion of other functional groups, ${ }^{2}$ and ring construction ${ }^{3,4}$ because the five-membered ring can be formed in a single step. In addition, the products are readily transformed into polyfunctionalized compounds upon cleavage of the $\mathrm{N}-\mathrm{O}$ bond. On the other hand, nitrile oxide $\mathbf{1}$ is too unstable to be isolated, although its generation can be confirmed by spectroscopy. ${ }^{5}$ Vacuum pyrolysis ${ }^{6}$ or base-induced dehydrochlorination ${ }^{7,8}$ of chloro(cyano)formoxime $\mathbf{2}$ are common methods used to generate nitrile oxide $\mathbf{1}$. In addition, the pyrolysis of dicyanofuroxan $3^{9}$ and treating nitroacetonitrile 4 with ammonium cerium(III) nitrate ${ }^{10}$ are also effective approaches used to prepare 1 (Scheme 1). However, preparation of precursors 2 and 3 suffers from some drawbacks such as low yield, troublesome manipulations, and toxicity. ${ }^{11,12}$ In addition, nitroacetonitrile 4 should be handled as an explosive material (see ESI $\dagger$ ). ${ }^{3,13}$ Hence, the development of a safe and concise method for generation of cyanonitrile oxide $\mathbf{1}$ is highly desired.

Meanwhile, we have studied the application of dianionic cyano-aci-nitroacetate $\mathbf{5}^{\mathbf{1 4}}$ as a cyano(nitro)methylating agent in

\footnotetext{
${ }^{a}$ School of Environmental Science and Engineering,

Kochi University of Technology, Tosayamada, Kami, Kochi 782-8502, Japan.

E-mail: nishiwaki.nagatoshi@kochi-tech.ac.jp

${ }^{b}$ Research Center for Material Science and Engineering,

Kochi University of Technology, Tosayamada, Kami, Kochi 782-8502, Japan

$\dagger$ Electronic supplementary information (ESI) available: Experimental methods, monitoring experiments using ${ }^{1} \mathrm{H}$ NMR, DSC measurement, and copies of ${ }^{1} \mathrm{H}$ and

${ }^{13} \mathrm{C}$ NMR spectra. See DOI: $10.1039 / \mathrm{c} 9 \mathrm{cc} 03875 \mathrm{~b}$
}

organic synthesis leading to the synthesis of functionalized heterocyclic systems. ${ }^{3,15}$ The structure of 5 can be regarded as a masked form of cyanonitrile oxide 1 , based on which we envisaged that nitrile oxide $\mathbf{1}$ should be generated upon protonation of dianion 5 accompanied by decarboxylation and dehydration.

Although it is possible to isolate dianion $\mathbf{5}$, decarboxylation gradually occurs. ${ }^{14}$ Thus, 5 was generated in situ via a ring opening reaction of pyridinium salt 6 upon treatment with $N$-methylpyrrolidine. A solution of 6 and ethynylbenzene 7a in acetonitrile showed no change even when heated at $100{ }^{\circ} \mathrm{C}$ for $1 \mathrm{~d}$ in a sealed tube (Table 1, entry 1 ). On the other hand, a trace amount of 3-cyano-5-phenylisoxazole $(\mathbf{8 a})^{16}$ was obtained when the reaction was conducted under the same conditions in the presence of acetic acid (entry 2). The addition of a stronger acid
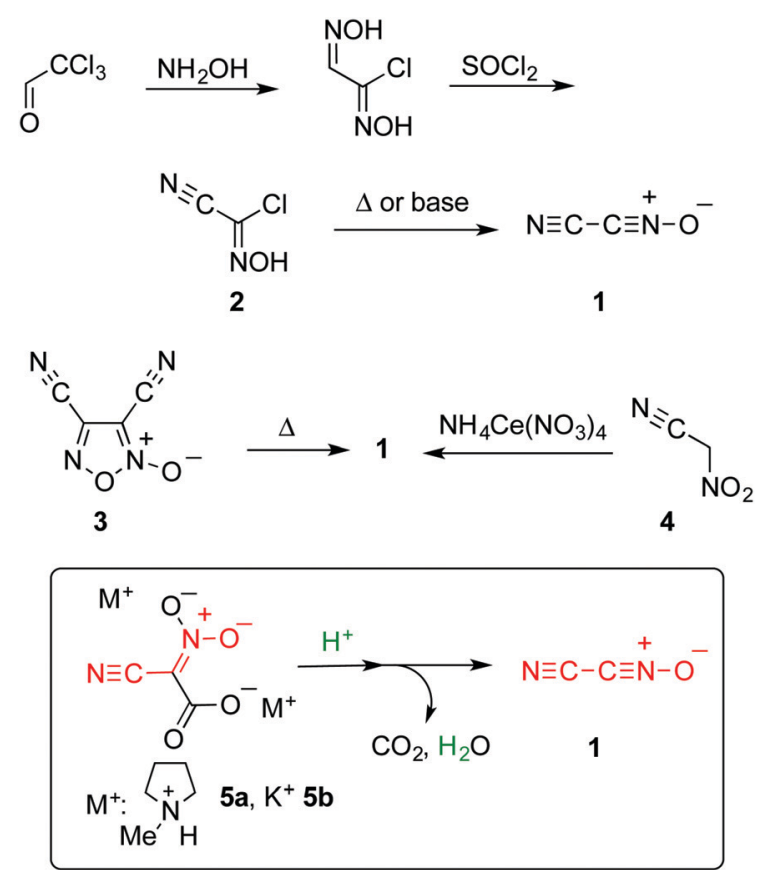

Scheme 1 Methods for the synthesis of cyanonitrile oxide 1 
Table 1 Assessment of the acid used in the cycloaddition reaction

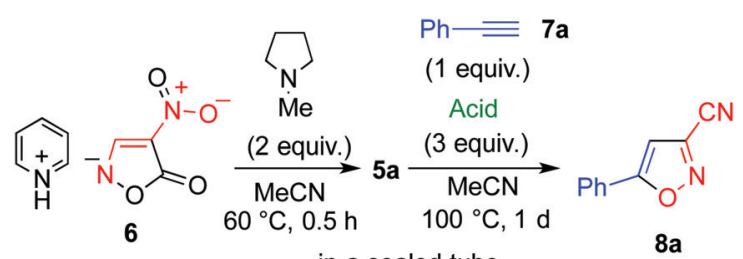

in a sealed tube

\begin{tabular}{lll}
\hline Entry & Acid & Yield $/ \%$ \\
\hline 1 & - & 0 \\
2 & $\mathrm{AcOH}$ & 5 \\
3 & $p-\mathrm{TsOH} \cdot \mathrm{H}_{2} \mathrm{O}$ & 15 \\
4 & $\mathrm{HCl}$ & 27
\end{tabular}

such as $p$-toluenesulfonic acid and hydrochloric acid, was found to be effective (entries 3 and 4 ).

To obtain further insight into this reaction, each step was monitored using ${ }^{1} \mathrm{H}$ NMR spectroscopy with deuterated acetonitrile used as the solvent (see ESI $\dagger$ ). Cation exchange of 6 occurred after addition of 1 equivalent of $N$-methylpyrrolidine, and the ring opening reaction occurred leading to formation of the dianion, $\mathbf{5 a}$, when another 1 equivalent of $N$-methylpyrrolidine was added. A new singlet signal appeared at $5.8 \mathrm{ppm}$ when hydrochloric acid was added to the solution of $\mathbf{5 a}$, in which nitroacetonitrile $\mathbf{4}$ or its anionic form $\mathbf{9 a}$ was formed as a result of the decarboxylation reaction, and either of these were considered to be the actual species in the cycloaddition reaction. Indeed, the formation of cycloadduct $\mathbf{8 a}$ was confirmed after heating this solution in the presence of $7 \mathbf{a}$.

Subsequently, a more stable dipotassium salt, $\mathbf{5 b}$, was employed from the viewpoint of its storage for a long period of time. Although 5a was more soluble in organic solvents, the reaction mixture was somewhat complicated because of the presence of pyridinium, pyrrolidinium, and ammonium chlorides, among which the last salt was formed during the acid-catalysed hydrolysis of acetonitrile. Thus, $\mathbf{5} \mathbf{b}$ was concluded to be more suitable for use as a reagent in organic synthesis.

Monopotassium salt $\mathbf{9 b},{ }^{14}$ derived from $\mathbf{5 b}$, did not afford any cycloadduct 8a upon heating with ethynylbenzene $7 \mathbf{a}$. However, the formation of $8 \mathbf{a}$ was confirmed when the same reaction was conducted in the presence of hydrochloric acid (Scheme 2). These results indicate that nitroacetonitrile 4 serves as a 1,3-dipole during the cycloaddition reaction.

The reaction conditions were optimized using dipotassium salt $\mathbf{5 b}$ (Table 2). A mixed solvent consisting of acetonitrile and water was suitable because it can dissolve both $\mathbf{5 b}$ and $7 \mathbf{a}$ (entries 1 and 2).

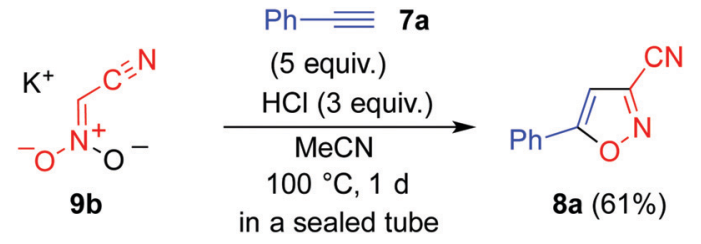

Scheme 2 The cycloaddition reaction using monopotassium salt $\mathbf{9 b}$ under acidic conditions.
Table 2 Optimization of the reaction conditions

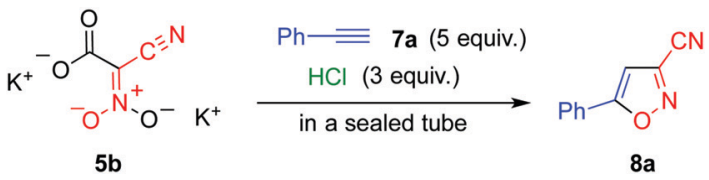

\begin{tabular}{lllll}
\hline Entry & Solv. & Temp. $/{ }^{\circ} \mathrm{C}$ & Time/h & Yield $/ \%$ \\
\hline 1 & MeCN & 100 & 24 & 78 \\
2 & $\mathrm{MeCN} / \mathrm{H}_{2} \mathrm{O}(1 / 4)$ & 100 & 24 & 90 \\
3 & $\mathrm{MeCN} / \mathrm{H}_{2} \mathrm{O}(1 / 4)$ & 70 & 24 & 0 \\
4 & $\mathrm{MeCN} / \mathrm{H}_{2} \mathrm{O}(1 / 4)$ & 100 & 3 & 0 \\
5 & $\mathrm{MeCN} / \mathrm{H}_{2} \mathrm{O}(1 / 4)$ & 100 & 6 & 43 \\
6 & $\mathrm{MeCN} / \mathrm{H}_{2} \mathrm{O}(1 / 4)$ & 100 & 12 & 96
\end{tabular}

However, no reaction occurred at lower temperature, which was presumably due to the low reactivity of nitroacetonitrile 4 when compared with conventional 1,3-dipoles such as nitrile oxide and nitrone (entries 2 and 3). Prolonging the reaction time was found to be effective for the reaction with cycloadduct 8a obtained in high yield after heating for $12 \mathrm{~h}$ (entries 4-6).

Under the optimized conditions dipolarophiles 7 and $\mathbf{1 0}$ were subjected to the cycloaddition reaction (Scheme 3). Electrondeficient alkyne $\mathbf{7 b}$ underwent the cycloaddition reaction to afford $\mathbf{8 \mathbf { b } ^ { 1 6 }}$ in quantitative yield. In contrast, alkenes $7 \mathbf{c}$ and 7d, which possess an electron-donating group furnished their corresponding cycloadducts $\mathbf{8 c}$ and $\mathbf{8 d}$ in moderate yields. Since considerable amounts of acetophenone derivatives were formed during these reactions, competitive hydration was considered to suppress the cycloaddition. trans-Stilbene 10e was also usable as a dipolarophile leading to the formation of diphenylisoxazoline 11e. Electron-deficient acrylates $10 \mathrm{f}$ and $\mathbf{1 0 h}$ also undergo the cycloaddition reaction efficiently, however, the ester functionality did not tolerate the reaction conditions, affording carboxylic acids $11 \mathrm{~g}$ and 11i, respectively. Conversely, it was possible to use
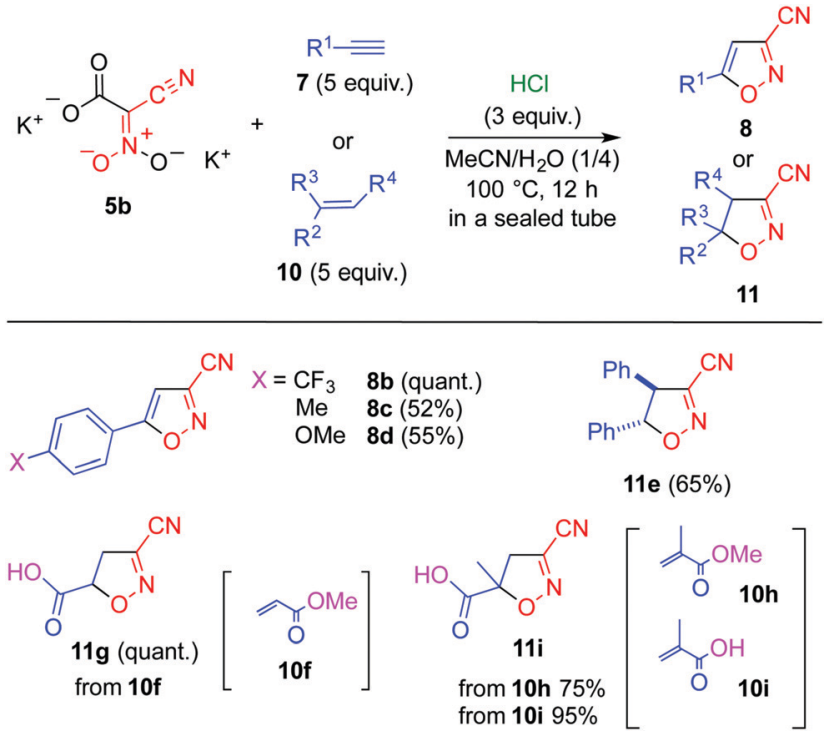

Scheme 3 Synthesis of 3-cyanoisoxazol(in)es $\mathbf{8}$ and $\mathbf{1 1}$. 
<smiles></smiles>
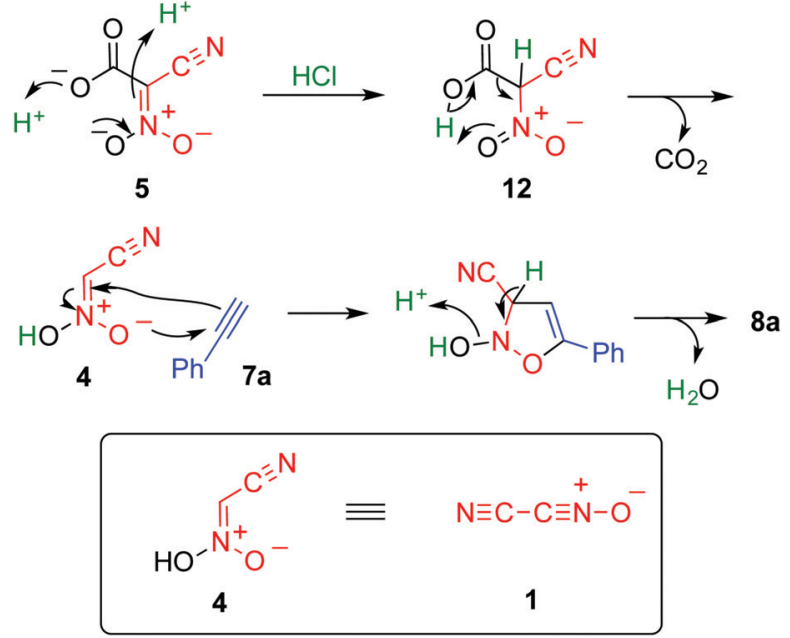

Scheme 4 A plausible mechanism for our 1,3-dipolar cycloaddition reaction.

carboxylic acid 10i as a substrate without protection in this reaction, which afforded 11i in high yield.

This reaction was considered to proceed as shown in Scheme 4. Protonation of dianion 5 affords 12, which immediately undergoes decarboxylation to give nitroacetonitrile 4 . The aci-nitro form of 4 serves as a 1,3-dipole and reacts with the dipolarophile to form a five-membered ring. Subsequent dehydration yields the final product. On the basis of this mechanism, the amount of acid necessary for this reaction is 2 equivalents. However, 3 equivalents of hydrochloric acid is necessary for an efficient reaction, which is presumably because the acid is also consumed by forming a salt with ammonia formed during the hydrolysis of acetonitrile.

To conclude, 3-cyanoisoxazol(in)es $\mathbf{8}$ and $\mathbf{1 1}$ were synthesized via the cycloaddition of nitroacetonitrile 4 . While nitroacetonitrile $\mathbf{4}$ is an explosive material, dianion $\mathbf{5}$ is thermally stable and can be stored for a long period of time without any special care. ${ }^{3,13}$ Hence, dianion 5 serves as a safe handleable synthetic equivalent of cyanonitrile oxide $\mathbf{1}$, which can be used as a novel tool in organic synthesis.

\section{Conflicts of interest}

There are no conflicts to declare.

\section{Notes and references}

\$ Typical procedure: in a screw capped test tube, dipotassium salt $5 \mathbf{b}(41.2 \mathrm{mg}, 0.2 \mathrm{mmol})$ was dissolved into a mixed solvent of $\mathrm{MeCN} /$ $\mathrm{H}_{2} \mathrm{O}(\mathrm{v} / \mathrm{v}=1 / 1,2 \mathrm{~mL})$. After adding 1-ethynyl-4-trifluoromethylbenzene $7 \mathbf{b}(144 \mu \mathrm{L}, 1 \mathrm{mmol})$ and $1 \mathrm{M} \mathrm{HCl}(3 \mathrm{~mL}, 3 \mathrm{mmol})$, the resultant mixture was heated at $100{ }^{\circ} \mathrm{C}$ for $12 \mathrm{~h}$ in a sealed tube. The solvent was removed under reduced pressure, and $\mathrm{MeCN}(10 \mathrm{~mL})$ was added to the residue. After filtration to remove the insoluble material, the filtrate was concentrated to afford 3-cyano-5-(4-trifluoromethylphenyl)isoxazole $8 \mathbf{b}$ (239 mg, $1 \mathrm{mmol}$, quant.) as a pale yellow solid. M.p. 92-95 ${ }^{\circ} \mathrm{C} .{ }^{1} \mathrm{H}$ NMR $\left(400 \mathrm{MHz}, \mathrm{DMSO}-d_{6}\right) \delta 8.04(\mathrm{~s}, 1 \mathrm{H}), 8.05(\mathrm{~d}, J=8.2 \mathrm{~Hz}, 2 \mathrm{H}), 8.23(\mathrm{~d}, J=$ $8.28 .2 \mathrm{~Hz}, 2 \mathrm{H}) ;{ }^{13} \mathrm{C}$ NMR (100 MHz, DMSO- $\left.d_{6}\right) \delta 105.0(\mathrm{CH}), 110.2(\mathrm{C})$, $123.7(\mathrm{C}, \mathrm{q}, J=271 \mathrm{~Hz}), 126.4(\mathrm{CH}, \mathrm{d}, J=3.5 \mathrm{~Hz}), 126.9(\mathrm{CH}), 128.7(\mathrm{C})$, 131.3 (C, q, $J=32.1 \mathrm{~Hz}), 140.3(\mathrm{C}), 170.3(\mathrm{C}) ; \mathrm{IR}\left(\mathrm{ATR} / \mathrm{cm}^{-1}\right)$ 2261, 1570, 1400, 1319; HRMS (ESI/TOF) calcd for $\left(\mathrm{M}+\mathrm{H}^{+}\right) \mathrm{C}_{11} \mathrm{H}_{6} \mathrm{~F}_{3} \mathrm{~N}_{2} \mathrm{O}: 239.0427$, found: 239.0428 .

1 S. U. Dighe, S. Mukhopadhyay, S. Kolle, S. Kanojiya and S. Batra, Angew. Chem., Int. Ed., 2015, 54, 10926; P. A. Wade and H. R. Hinney, J. Am. Chem. Soc., 1979, 101, 1319; P. A. Wade, J. Org. Chem., 1978, 43, 2020.

2 Recent reports: N. A. Bumagin, A. V. Kletskov, S. K. Petkevich, I. A. Kolesnik, A. S. Lyakhov, L. S. Ivashkevich, A. V. Baranovsky, P. V. Kurman and V. I. Potkin, Tetrahedron, 2018, 74, 3578; A. Nordqvist, G. O'Mahony, M. Friden-Saxin, M. Fredenwall, A. Hogner, K. L. Granberg, A. Aagaard, S. Baeckstroem, A. Gunnarsson, T. Kaminski, Y. Xue, A. Dellsen, E. Hansson, P. Hansson, I. Ivarsson, U. Karlsson, K. Bamberg, M. Hermansson, J. Georgsson, B. Lindmark and K. Edman, ChemMedChem, 2017, 12, 50; K. Natte, R. V. Jagadeesh, M. Sharif, H. Neumann and M. Beller, Org. Biomol. Chem., 2016, 14, 3356.

3 K. Iwai, H. Asahara and N. Nishiwaki, J. Org. Chem., 2017, 82, 5409.

4 M. Tamura, T. Nishimura, N. Nishiwaki and M. Ariga, Heterocycles, 2004, 63, 1659; N. Nishiwaki, T. Nogami, T. Kawamura, N. Asaka, Y. Tohda and M. Ariga, J. Org. Chem., 1999, 64, 6476; K. Gewald, P. Bellmann and H. J. Jaensch, Liebigs Ann. Chem., 1980, 1623.

5 G. K. Williams and T. B. Brill, Combust. Flame, 1998, 114, 569; R. Flammang, M. Barbieux-Flammang, P. Gerbaux, C. Wentrup and M. W. Wong, Bull. Soc. Chim. Belg., 1997, 106, 545; T. Pasinski and N. P. C. Westwood, J. Phys. Chem., 1996, 100, 16856; T. Pasinski and N. P. C. Westwood, J. Chem. Soc., Chem. Commun., 1995, 1901.

6 G. Maier and J. H. Teles, Angew. Chem., Int. Ed. Engl., 1987, 26, 155.

7 A. P. Kozikowski and M. Adamczyk, J. Org. Chem., 1983, 48, 366.

8 J. S. Lee, Y. S. Cho, B. Y. Chung and A. N. Pae, Bioorg. Med. Chem., 2003, 13, 4117; P. A. Wade and H. R. Hinney, Tetrahedron Lett., 1979, 139; C. Grundmann and H.-D. Frommeld, J. Org. Chem., 1966, 31, 4235.

9 T. Shimizu, Y. Hayashi, T. Taniguchi and K. Teramura, Tetrahedron, 1985, 41, 727.

10 T. Sugiyama, Appl. Organomet. Chem., 1995, 9, 399.

11 H. Mohler, Protar, 1941, 7, 57.

12 C. He and J. M. Shreeve, Angew. Chem., Int. Ed., 2016, 55, 772; L. L. Fershtat, M. A. Epishina, A. S. Kulikov, I. V. Ovchinnikov, I. V. Ananyev and N. Nina, Tetrahedron, 2015, 71, 6764; T. M. Mel'nikova, T. S. Novikova, L. I. Khmel'nitskii and A. B. Sheremetev, Mendeleev Commun., 2001, 30.

13 C. J. Thomas, Chem. Eng. News, 2009, 87(32), 4.

14 N. Nishiwaki, Y. Takada, Y. Inoue, Y. Tohda and M. Ariga, J. Heterocycl. Chem., 1995, 32, 473.

15 N. Nishiwaki, Curr. Med. Chem., 2017, 24, 3728; H. Asahara, K. Muto and N. Nishiwaki, Tetrahedron, 2014, 70, 6522; N. Nishiwaki, T. Nogami, T. Kawamura, N. Asaka, Y. Tohda and M. Ariga, J. Org. Chem., 1999, 64, 6476; N. Nishiwaki, T. Nogami, C. Tanaka, F. Nakashima, Y. Inoue, N. Asaka, Y. Tohda and M. Ariga, J. Org. Chem., 1999, 64, 2160.

16 N. A. Bumagin, A. V. Kletskov, S. K. Petkevich, I. A. Kolesnik, A. S. Lyakhov, L. S. Ivashkevich, A. V. Baranovsky, P. V. Kurman and V. I. Potkin, Chem. Heterocycl. Compd., 2014, 49, 1515. 